\title{
Narrative risk messages increase uptake and sharing of health interventions in a hard-to-reach population: A pilot study to promote milk safety among Maasai pastoralists in Tanzania
}

Mark A. Caudell ${ }^{1,2^{*}}$ (D, P. Victor Charoonsophonsak ${ }^{3}$, Annalise Miller $^{4}$, Beatus Lyimo $^{5}$, Murugan Subbiah ${ }^{1}$, Joram Buza ${ }^{5}$ and Douglas R. Call ${ }^{1,5}$

\begin{abstract}
Across pastoralist groups, dairy products often fulfill major nutritional, economic, and socio-cultural functions. These contributions are jeopardized by poor milk quality with studies among pastoralist groups showing dairy products can harbour a long list of pathogens. These potential risks underscore the need for more effective dairy hygiene interventions. Here, we determine how health messages advocating the "novel" method of pasteurization versus boiling, and administered in narrative versus technical formats, can have an impact on hygiene practices and milk quality in Maasai pastoralists. Four Maasai villages in northern Tanzania were purposively selected to receive intervention strategies that varied in message format (narrative or technical) and heat treatment advocated (boiling or pasteurization). Census lists were used to randomly select 30-35 households in each village $(N=125)$. Across three visits, milk hygiene knowledge and attitudes were monitored, hygiene practices were directly measured by smart thermometers that recorded heat treatment, and milk quality was determined by calculating total bacterial counts (TBCs) $(N=1007)$. Compared to initial levels, TBCs in the pasteurization-narrative village $(N=33)$ exhibited a $73.4 \%$ decrease (OR 0.148-0.480) after 7 days and a 59.1\% decrease (OR 0.216-0.734) after 14 days. The boilingnarrative $(N=28)$ exhibited a significant decrease at 7 days $(-68.8 \%$, OR $0.161-0.606)$, but this decrease was not significant after 14 days ( $-35.5 \%$, OR 0.322-1.253). There were no significant decreases for the pasteurizationtechnical $(N=29)$ or boiling-technical $(N=31)$ villages after 7 or 14 days. In addition, narrative health formats led to significantly greater retention of health messages and peer-to-peer sharing. Interventions to improve milk quality in pastoralist and other livestock-dependent communities may benefit from enabling the "novel" method of pasteurization. More broadly, our results suggest that the use of narrative messages can promote healthy behaviours when cultural norms are contrary to best health practices as well as enhance the sustainability and scalability of interventions targeted at hard-to-reach populations, including most pastoralist communities.
\end{abstract}

Keywords: Milk safety, Risk communication, Pastoralists, Maasai, Africa

\footnotetext{
* Correspondence: mcaudell@wsu.edu

'Paul G. Allen School for Global Animal Health, Washington State University,

240 SE Ott Road, Pullman, WA 99164-7090, USA

${ }^{2}$ Department of Anthropology, Washington State University, Pullman, WA,

USA

Full list of author information is available at the end of the article
} 


\section{Introduction}

Dairy production is recognized as an effective strategy to improve food security among pastoralists and other livestock-dependent groups given that dairy products often provide considerable caloric and nutritional resources (Food and Agriculture Organization of the United Nations (FAO) 2008; Dror and Allen 2011). Indeed, in some pastoralist communities, dairy products can comprise over half of the daily caloric intake (Galvin 1992; Lindtjørn et al. 1993; Homewood 1995; Barasa et al. 2008), although this contribution varies considerably across seasons (wet vs dry), ecologies (highland vs lowland), and livestock species kept. Dairy products provide sources and concentrations of nutrients not found in other dietary staples (e.g. grains) including high-quality proteins, calcium, zinc, and vitamins $\mathrm{B}_{6}$ and $\mathrm{B}_{12}$ (Muehlhoff et al. 2013; Galli and Risé 2017).

Access to dairy products is particularly important for the welfare of pastoralists who remain some of the most nutritionally vulnerable communities within low- and middle-income countries (LMICs) (Fratkin et al. 2006; Lawson et al. 2014). Maasai children in Tanzania, for example, are almost two times as likely to exhibit stunted growth compared to crop-reliant and urban communities (Lawson et al. 2014). In addition, pastoralist women experience more complications during pregnancy and give birth to lower weight infants (Black et al. 2013; Bakhtsiyarava et al. 2017). Importantly, dairy consumption is associated with linear growth, thereby reducing the likelihood of stunting (Allen 1994; Xueqin et al. 2004; Hoppe et al. 2006). Milk consumption during pregnancy has been shown to promote maternal weight gain, placental growth, foetal growth, and increased birth weight, particularly in malnourished populations (Hoppe et al. 2006; Ludvigsson and Ludvigsson 2007; Dror and Allen 2011; Michaelsen 2013; Hjertholm et al. 2017; Wiley 2017). In light of these benefits, supporting dairy production among pastoralists is rendered even more critical, given recent studies indicating the dietary contributions from dairy are decreasing in pastoralist communities, likely due to expanding human populations combined with decreases in rangeland size, leading to an overall reduction in the human/livestock ratio (Homewood et al. 2009; Sadler et al. 2010).

Efforts to support dairy production in pastoralist communities are also challenged by the production and consumption of milk contaminated with pathogens (e.g. bacteria, viruses), which can constrain and even reverse the associated beneficial effects (Muehlhoff et al. 2013). Dairy products sampled from pastoralist and other livestock-dependent groups have been shown to harbour a long list of microorganisms, including pathogenic bacteria such as Brucellosis, Salmonella, Mycobacterium, Listeria, Campylobacter, Coxiella, Staphylococcus aureus, and Escherichia coli (Ateba et al. 2010; Asrat et al. 2013; Lubote et al. 2014; Jans et al. 2017). These products have also been shown to be a source of antibiotic-resistant bacteria (Ateba et al. 2010; Zanella et al. 2010; Ahmed et al. 2012; Suleiman et al. 2013; Mbuk et al. 2016). Indeed, the current authors found that consumption of raw milk was a significant risk factor for carriage of antibiotic resistance in Maasai pastoralists (Caudell et al. 2018), suggesting that milk consumption is a substantial but largely underappreciated risk factor in the transmission and evolution of antimicrobial resistance.

Given that most pastoralist communities consume milk produced from within the household, interventions to support dairy hygiene must be targeted at the household level. In particular, the health risk posed by milk is dramatically reduced by boiling or pasteurizing milk immediately before consumption. Both pasteurization (raising temperature to $\approx 70{ }^{\circ} \mathrm{C}$ for $\left.\approx 15 \mathrm{~s}\right)$ and boiling $\left(\approx 100^{\circ} \mathrm{C}\right)$ kill the vast majority of microorganisms. However, while boiling is often assumed to be a common practice, surveys suggest considerable variation in observance, particularly among pastoralist populations (Geoghegan et al. 2013; Koné et al. 2014; Mangesho et al. 2017). Surveys within East and South African communities have documented self-reported boiling rates as low as 3\% of households (Geoghegan et al. 2013), although self-reported rates between 30 and 60\% appear to be more common (Bertu et al. 2010; Roug et al. 2014; Caudell et al. 2017). In West Africa, boiling of milk is uncommon and even considered taboo in some pastoralist communities (Koné et al. 2014). In addition, the effectiveness of heat treatment is compromised when other hygienic practices are not followed including washing hands, udders, and milk containers with water and soap. Observance of these practices among pastoralists is often considerably lower compared to heat treatment with rates of washing udders and observance of withdrawal from antibiotics particularly low (typically 5-10\%) (Karimuribo et al. 2005; Negash et al. 2012; Welearegay et al. 2012; Duguma and Janssens 2015). Poor hygiene practices are consistent with findings that total bacterial counts (TBCs) from samples of raw milk are not significantly different from those of heat-treated milk (Shija 2013).

While observance of hygiene practices may be low, many communities appear to recognize the importance of hygienic milking practices (Schoder et al. 2013; Ngasala et al. 2015). Consequently, why is observance so limited? In pastoralist communities, a major reason stems from the significant cultural and religious roles that dairy and livestock in general fulfill, which impact beliefs on contamination, contagion, and cleanliness (Ibrahim 2001; Sadler et al. 2010; Roulette et al. 2018). Among Maasai pastoralists, for example, milk is used to clean the knife to perform circumcision rituals (emuratare) and to wet hair during naming ceremonies of newborns and is 
sprinkled on moran (traditional warriors) when they graduate from warrior to the elder stage (Ibrahim 2001). These roles bestow dairy products with an element of purity that often constrains beliefs that the products can be unclean. Mangesho et al. (2017) found that since milk is the "source of life", among the Maasai it "cannot be associated with anything bad" (p. 15, quoting a Maasai elder). In addition, the Maasai believed that raw milk, compared to boiled milk, stays for a longer time in the stomach and has more fat to keep one warm (Mangesho et al. 2017). These results are consistent with our own work among the Maasai, which found that raw milk was believed to have "complete nutrients", was "thick", and helped "build the body" and "give energy". On the other hand, boiled milk was viewed as lacking complete nutrients, as being thin "like water", and as causing constipation (Roulette et al. 2017). Many Maasai also believed that the use of soap in cleaning containers impacted the taste of milk. Soap is never used, for example, to clean traditional gourd milking containers (ingri). Instead, gourds are rinsed with water and sometimes with cow urine and then cleaned with brushes made from roots of olmukatan (Albiza anthelmintica) or oiti (Acacia mellifera) trees. Calabashes are then dried and "disinfected" with coals of oloirien (Olea Africana), a sacred tree within the Maasai, giving milk a slight charcoal taste (Roulette et al. 2017). Collectively, these beliefs increase the likelihood that milk contaminated with pathogens is consumed.

\section{Pasteurization as a culturally conscious method of heat treatment}

The cultural and social significance of dairy within pastoralist systems combined with studies documenting limited observance of important hygiene practices demonstrates that novel methods of heat treatment and risk communication are needed to improve milk quality in pastoralist communities. Considering the apparent ineffectiveness of public health campaigns advocating boiling, one potential solution is to provide pastoralist households with the technological inputs to enable milk pasteurization. Pasteurization, as it requires a lower level of heat $\left(\approx 70^{\circ} \mathrm{C}\right.$ vs $\left.\approx 100^{\circ} \mathrm{C}\right)$, produces a product that tastes more like raw milk relative to boiled milk and takes less time and resources (e.g. firewood).

To determine if households would adopt pasteurization practices as an alternative to boiling milk, a pilot study was conducted during the summer of 2015 in two Maasai pastoralist villages. We dispensed simple kitchen thermometers with training to women $(N=57)$ and found that after 2 months, Maasai women favoured milk pasteurization over boiling (Roulette et al. 2017) (see Fig. 1). However, a number of Maasai women were no longer using the thermometers because they were hard to see in low-light households or the thermometers had been broken. In addition, while
Maasai women reported using the thermometers, we did not have any direct evidence of use (e.g. a record of the number of times the thermometers were used) or whether advocating pasteurization actually produced an increase in milk quality (e.g. decreased bacterial loads). Using feedback provided by Maasai women during this pilot, we designed a smart thermometer that we disseminated among Maasai women for the current study. The thermometer (1) lights up when milk has been successfully heat-treated, thereby enabling use in low-light environments; (2) is constructed from a robust plastic polymer to limit breakage; and (3) records the number of times the thermometer was used (see Additional file 1: p. 1 for more detail on the thermometer design).

\section{Narrative risk messages to promote behavioural change}

Even with "culturally tuned" hygiene practices that consider the cultural norms of milk consumption and production, pastoralists may not adopt hygienic milking practices if they do not perceive milk as a potential health risk, even if they recognize the risks as ethnographic work suggests (see above and Koné et al. 2014; Mangesho et al. 2017; Roulette et al. 2017). Again, while many communities recognize the importance of hygienic practices, studies suggest limited observance of these practices. Research within risk communication suggests that the effectiveness of health messages to change attitudes and practices can be enhanced when risks are communicated in narrative or story formats, especially within low-health-literacy populations (Goddu et al. 2015; Moran et al. 2016). Narrative messages embed health information "within a representation of connected events and characters that has an identifiable structure, is bounded in space and time and contains explicit or implicit messages about the topic being addressed" (Kreuter et al. 2007, p. 222). The narrative approach differs from the more customary technical/didactic health message, which attempts to communicate risk through facts and numbers (e.g. 23,000 people in the USA die from antibiotic-resistant infections per year). Narrative messages create behavioural change by eliciting more powerful emotional responses compared to technical messages as people become immersed within a story storyline (Green and Brock 2000; Kreuter et al. 2007), which also suppresses counterarguing (i.e. when people's previously held beliefs lead to rejection of the risk message) (Green and Brock 2000). A recent meta-analysis of studies showed that narrative messages were more effective in producing knowledge gains and changes in attitude and behaviours compared to technical messages, although the effect size was small (Shen et al. 2015).

Herein, we examine how different milk-hygiene messages produce knowledge gains and changes in attitudes and behaviours within a low-health-literacy pastoral 


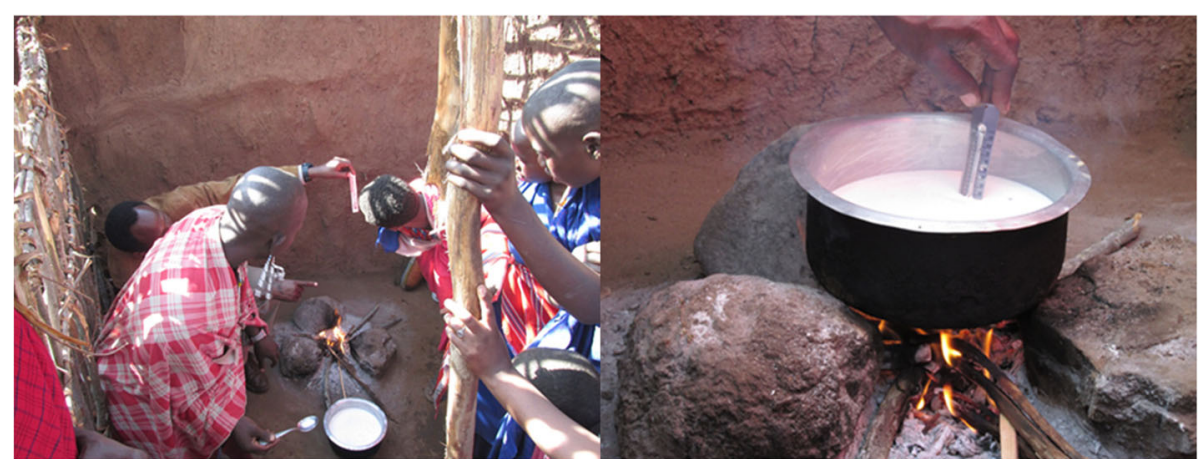

Fig. 1 Training Maasai women how to pasteurize milk in 2015

community while testing the hypotheses that (1) intervention messages advocating milk pasteurization will produce higher rates of milk heat treatment and better milk quality compared to messages advocating boiling and that (2) intervention messages delivered in narrative formats will result in greater knowledge retention, sharing of the intervention message, higher rates of heat treatment, and better milk quality compared to messages delivered in technical formats.

\section{Study area}

The study was carried out in four Maasai communities in Arusha and Manyara regions in northwest Tanzania (see Fig. 2). Communities are similar in terms of climate, vegetation type, and terrain. Elevation ranges between 1400 and $1600 \mathrm{~m}$ above sea level. Average annual rainfall is around $500 \mathrm{~mm}$, making these communities fall within the semi-arid ecological zone. Rainfall is bimodal with short rains falling between November and January and long rains between March and May. In more recent times, however, the rains are becoming much less predictable and the short rains often fail entirely (Msoffe et al. 2011). Vegetation is dominated by woody shrubs and trees particularly Acacia tortilis, Acacia nilotica, and Commiphora africana which are common throughout the area. Soils are mostly red clay and light sandy soils (Sangeda and Maleko 2018).

\section{The Maasai}

The Maasai and related Maa-speaking pastoralists are found throughout Tanzania and Kenya. Patrilocal, extended family homesteads boma or enkang are the units of production and function as corrals for livestock when animals are not traveling with moran ("warriors") in

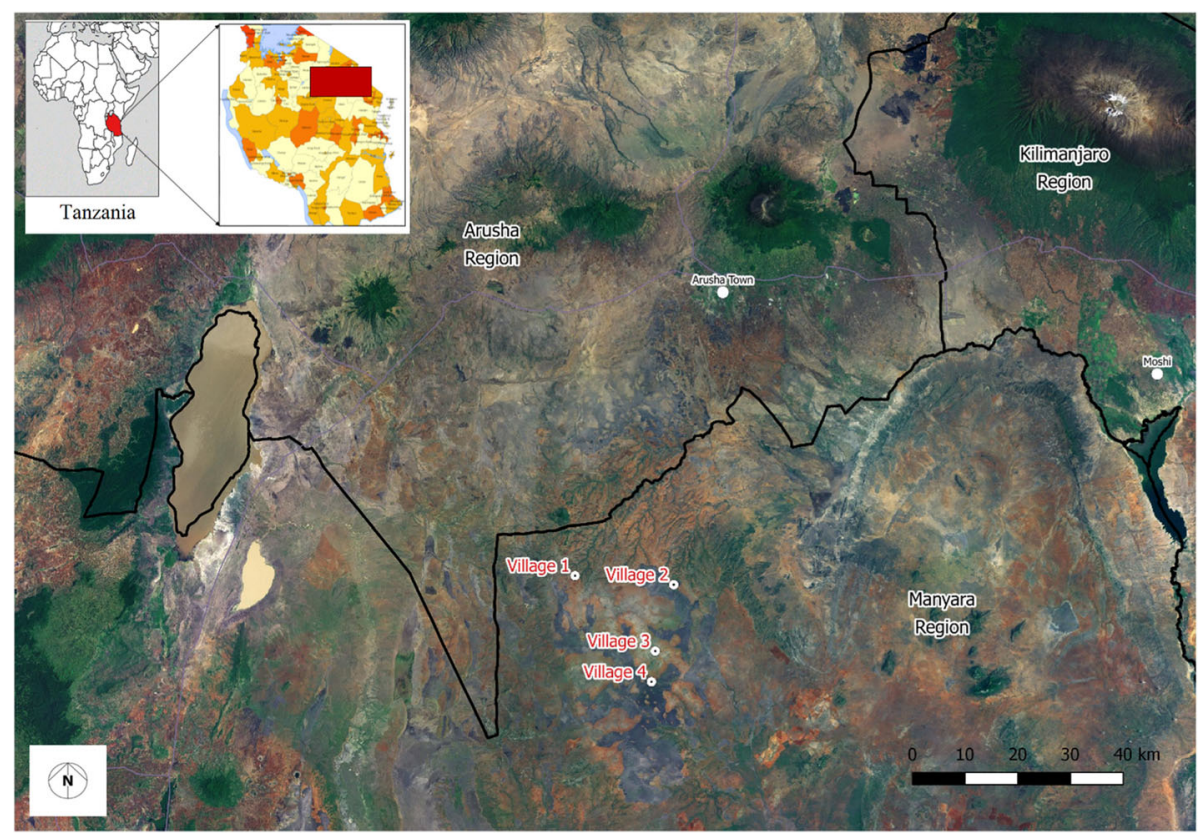

Fig. 2 Map of the study area 
search of water and grass. Traditionally, the Maasai were nomadic pastoralists who moved with their herds in search of grass and water. Today, most Maasai are agro-pastoralists who grow some crops (mostly maize and beans) and keep cattle, sheep, goats, and free-range poultry (McCabe et al. 2010). Livestock products, however, remain dietary staples for the Maasai and livestock continue to play important economic and symbolic roles. As with other East African pastoralists, cattle are primarily seen as milk producers and not as sources of meat or trade (Little et al. 2001). Milk and milk products (e.g. butter) contribute between a third and half of the energy in the Maasai diets (Homewood 1992; Homewood 1995). Milk is consumed raw, fermented into sour milk/butter, or boiled. Raw milk can be stored for up to $12 \mathrm{~h}$ (no access to refrigeration) although it is often consumed earlier, while sour milk may be stored for up to 1 to 2 weeks (Caudell et al. 2017).

\section{Methods Study design}

Across 124 randomly selected households in four Maasai villages, we determined the effectiveness of one of four intervention conditions: a technical message advocating boiling (BT), a narrative message advocating boiling (BN), a technical message advocating pasteurization (PT), and a narrative message advocating pasteurization (PN). Enrolled households within a village received the same condition, which was randomly assigned across the four villages. Village selection was purposive and based on the criteria that (1) they were geographically separated (avg. $20 \mathrm{~km}$ apart), (2) milk would likely be available during the intervention period, and (3) the village had not been subject to milk-hygiene interventions in the past.

\section{Randomization}

Households were selected by consulting lists of Maasai bomas provided by local village offices. Thirty to 35 bomas were randomly selected by the first author from these lists. Bomas were visited, and one household within each boma was randomly selected by the first author using the runinform function in Stata 13 (StataCorp 2012). The number of eligible households within bomas ranged from 2 to 32 households.

\section{Procedures}

Immediately following our initial baseline visit, the health intervention was administered. The health message focused on several key points including the following: (1) Bacteria are small bugs that you cannot see with your eyes but that can make you sick if you consume them. (2) These bacteria can live in milk and in dirty calabashes, cups, and pots that have not been cleaned with soap and water. (3) To make you and your family safe against bacteria in milk and cups/pots, you must heat-treat your milk, clean your containers with soap and water, and cover milk if storing for any length of time. The narrative message was a story about a Maasai woman who was not practising proper hygiene, so her children became sick and she had to go through all the troubles of getting treatment. Message specifics were developed through focus group discussions with unenrolled Maasai women (see Additional file 1: p. 4 for details on message development and an example vignette). After conveying intervention messages, an assistant would hand out smart thermometers, soap in 50-ml conical tubes, sponges, and pot covers. The assistant would then demonstrate how to properly use each item (see Fig. 3). Households that were told to boil their milk were given thermometers that emitted a light when the milk had reached the boiling temp $\left(\approx 100^{\circ} \mathrm{C}\right)$. Households that were told to pasteurize their milk were given thermometers that emitted light after the milk had maintained $\approx 70{ }^{\circ} \mathrm{C}$ for $15 \mathrm{~s}$. During the second and third household visits, we downloaded thermometer data of heating events, measured the amount of soap consumed (in millilitres), assessed issues with the intervention (e.g. thermometer not working properly), collected data on the sharing of interventions with friends and neighbours, and sampled milk and containers. During the third visit, we administered a knowledge exam to assess retention of the key intervention messages.

For our sample collections, household members provided us with milk that they would drink "as is" and containers they would use (drink out of, cook with) "as is". For liquid samples, $10-20 \mathrm{ml}$ of milk was collected and poured into a sterile $50-\mathrm{ml}$ polypropylene tube. For swabs, sterile water was poured over a cotton ball that was used to rub the insides and rim of storage containers. Swabs were then placed into $50-\mathrm{ml}$ conical tubes with $10 \mathrm{ml}$ sterile water. Samples were transported in a mobile refrigerator $\left(4^{\circ} \mathrm{C}\right)$ before processing at the Nelson Mandela Institution of Science and Technology (NM-AIST) in Arusha, Tanzania. For liquid milk samples, $50 \mu \mathrm{l}$ of milk was plated on MacConkey agar plates by using sterile glass beads. For swab samples, the cotton was aseptically squeezed between the fingers, and $100 \mu \mathrm{l}$ of the resulting suspension was plated on MacConkey agar plates. Plates were put into a stationary incubator for $16-18 \mathrm{~h}$ at $37^{\circ} \mathrm{C}$. If bacterial colonies were too numerous to count, serial dilutions were prepared in sterile water (1:10, 1:100, 1:1000). All samples were kept refrigerated until bacterial counts could be confirmed. Counts were converted to number of bacteria per millilitre of the original sample. Note that MacConkey agar allows growth of aerobic Gram-negative bacteria (e.g. coliforms) while inhibiting growth of Gram-positive 


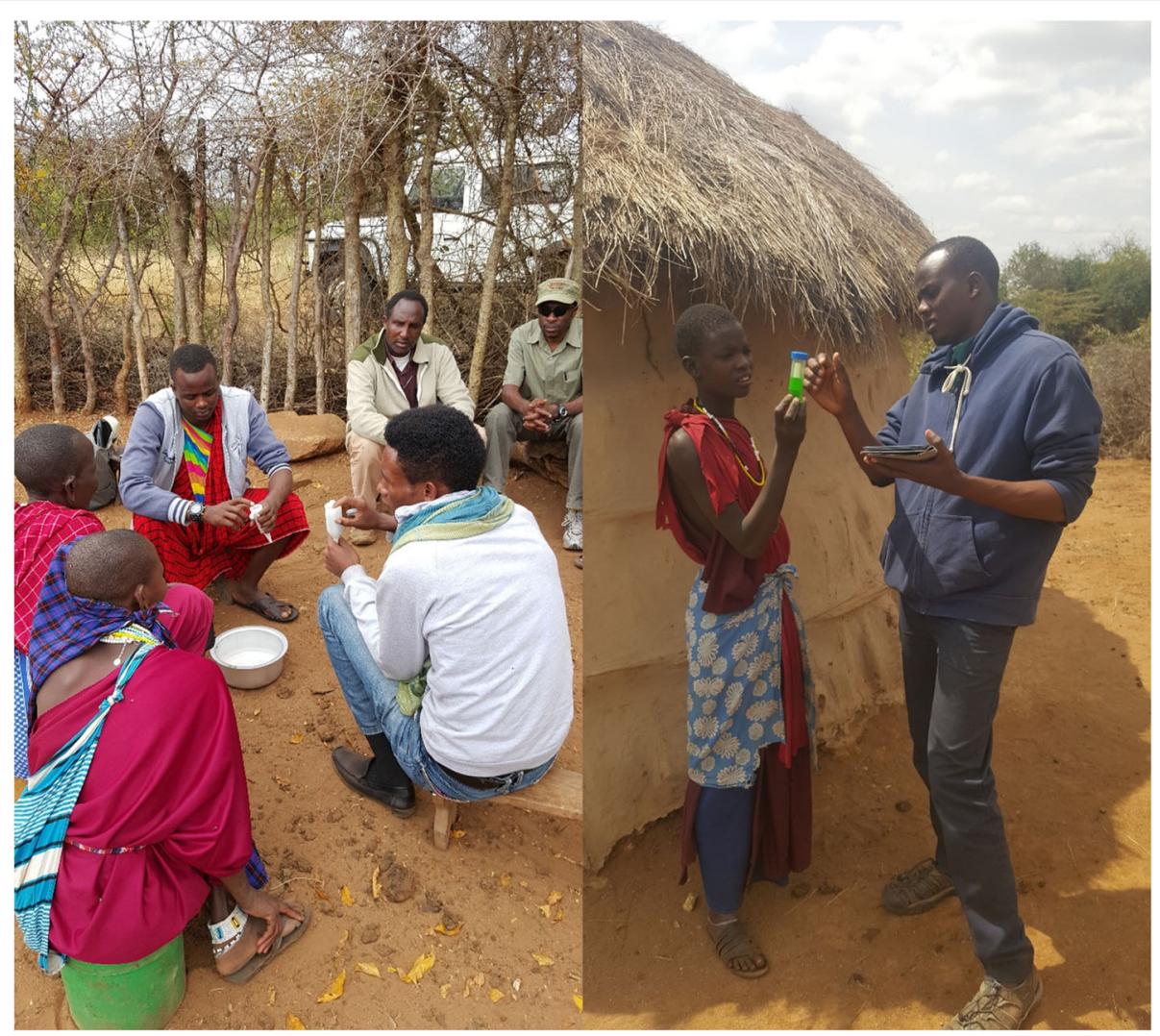

Fig. 3 Teaching Maasai women how to use the thermometers and measuring soap consumption

bacteria. The average time between collection and processing at NM-AIST, Tanzania, was $9 \mathrm{~h}$.

\section{Outcomes}

Our primary outcome to assess intervention effectiveness was the change in TBCs of liquid milk samples and swabs of milk containers across the three time periods. Secondary outcomes included the number of times the thermometer was successfully used, the number of people to whom a person enrolled in the study shared the intervention messages with, the amount of soap left in vials, and the retention of key intervention messages.

\section{Statistical analysis}

Due to strong evidence of over-dispersion $\left(G^{2}=111,448, P\right.$ $<0.01$ ), we used a negative binomial regression to model decreases in TBCs across the four villages and three time periods. Given the hierarchical nature of our data (samples collected within households), we controlled for clustered observations by allowing intra-group correlations when estimating standard errors for the single-level analysis. A multi-level approach was initially considered, but comparison of Akaike information criterion between multi-level and single-level models demonstrated no significant improvement in model fit $\left(G^{2}=3.2, P=0.75\right)$. Additionally, calculation of intra-class correlation values indicated that only $3 \%$ of variation in TBCs was accounted for by household membership. Negative binomial coefficients are reported as incident rate ratios and transformed into discrete changes using Long and Freese (2006). As such, they can be interpreted in a similar way to odds ratios, with coefficients above 1 indicating an increase in likelihood and those below 1 a decrease in likelihood. To further facilitate interpretation, we also plot the model-predicted changes in TBCs across the four villages and across the three time periods.

The main predictor variable entered into our models of TBC was the intervention strategy a household was administered. Secondary predictor variables included household size, scales of hygiene beliefs, hygiene practices, and women's achieved status. Achieved status was a scale that combined education level, proficiency in $\mathrm{Ki}$ swahili, and status as a leader in local churches or government. We also included women's score on a pathogen avoidance scale, which was an 8-item scale measuring a person's aversion to germs (Duncan et al. 2009). See Additional file 1: p. 13 for questions comprising hygiene beliefs and practices and detailed explanations of achieved status and pathogen avoidance scales. Control variables entered into the models included whether the milk sample was raw or heat-treated, 
whether the sample was liquid milk or from a container swab, the type of container the milk was poured out of (i.e. calabash, metal cup, plastic, or metal pot), whether soap was reportedly used to clean the container, and the time between collection and lab processing. To facilitate interpretations of $\mathrm{TBC}$ differences between intervention strategies, four models were specified that differed in the intervention control. We present the model with pasteurization-narrative as a control in the main text and provide results of the other models in Additional file 1: pp. 6-8.

Due to the smaller sample size at the household level $(N=124)$, we use a forward stepwise regression approach to model person-level outcomes (i.e. sharing, knowledge retention, thermometer and soap use) with an inclusion criterion of $P=0.1$, with exception of village controls that were retained in models (see Additional file 1: pp. 9-12 for full models). Intervention sharing was significantly over-dispersed $\left(G^{2}=15.2, P<0.01\right)$, and so a negative-binomial regression was used. Ordinary least squares (OLS) regression was used to model the remaining outcomes, and coefficients are interpreted as the mean change in the outcome variable (i.e. sharing of messages, knowledge retention, thermometer and soap use) while holding other predictor and control variables constant. Model assumptions and fit were assessed for each model. In general, there were no substantial deviations from model assumptions and overall model fits were good (see Additional file 1: p. 14 for discussion of diagnostics).

\section{Results}

\section{Patterns of milk consumption, hygiene practices, and milk quality}

Across the four villages, milk-hygiene knowledge, attitudes, and practices (KAP) and dairy consumption patterns across both milk products (e.g. raw, boiled) and household member type (wife, children, etc.) were not significantly different (one-way ANOVA, $P>0.05$; Fig. 4 and Additional file 1: p. 3). Pre-intervention TBCs for milk (avg. $10,820 \mathrm{cfu} / \mathrm{ml}, \mathrm{sd}=22,034$; see Fig. 2) were significantly different across villages $(F(3,1003)=4.7 P=0.002)$ where $\mathrm{TBCs}$ were lower in the $\mathrm{BT}$ village compared to those in the the PT $(-5170 \pm 1892, P=0.032)$ and the pasteurization-narrative $(-6392 \pm 1861, P=0.003)$ villages (Tukey's post hoc multiple comparison test).

\section{Impact of intervention type on milk quality}

Across the intervention period, the pasteurization-narrative $(\mathrm{PN})$ message was associated with the largest decrease in total bacterial counts in milk and milking containers when controlling for household demographics, KAP measures, pathogen avoidance, and sample characteristics (e.g. liquid versus raw). Compared to pre-intervention counts, TBCs decreased by $\approx 73 \%$ after 7 days and remained $\approx 60 \%$ lower after 14 days (Fig. 5 , Table 1 ). This decrease was significantly greater compared to the boiling-technical (BT) village across the intervention period at both time periods as well as compared to the pasteurization-technical (PT) village at 14days (Table 1). TBC decreases in PN villages were not significantly different from those in boiling-narrative (BN) villages at 7 or 14 days post-intervention. The $\mathrm{BN}$ village exhibited a significant decrease at 7 days $(-68.8 \%)$, but this decrease was not significant after 14 days $(-35.5 \%)$. There were no significant decreases in the PT village after $7(-55.0 \%)$ or 14 days $(+3.4 \%)$ or in the BT village after 7 $(-12.8 \%)$ or 14 days $(-2.3 \%)$.

When controlling for household demographics, KAP measures, pathogen avoidance, and other sample characteristics, milk reported as heat-treated had lower TBCs compared to raw milk $(\approx 35 \% ; P=0.001)$; samples from metal cups had lower TBCs compared to plastic, calabashes, and metal pots $(\approx 46 \% ; P=0.001)$; and containers

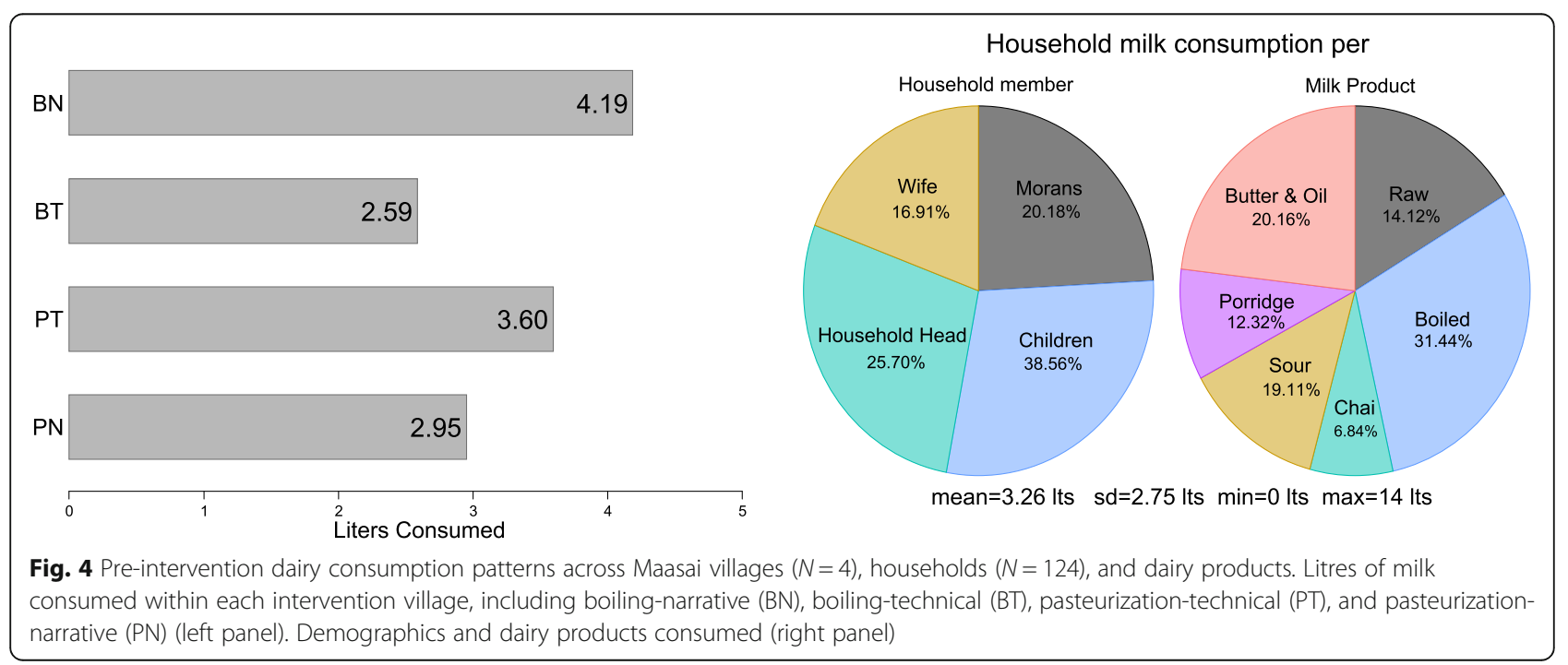




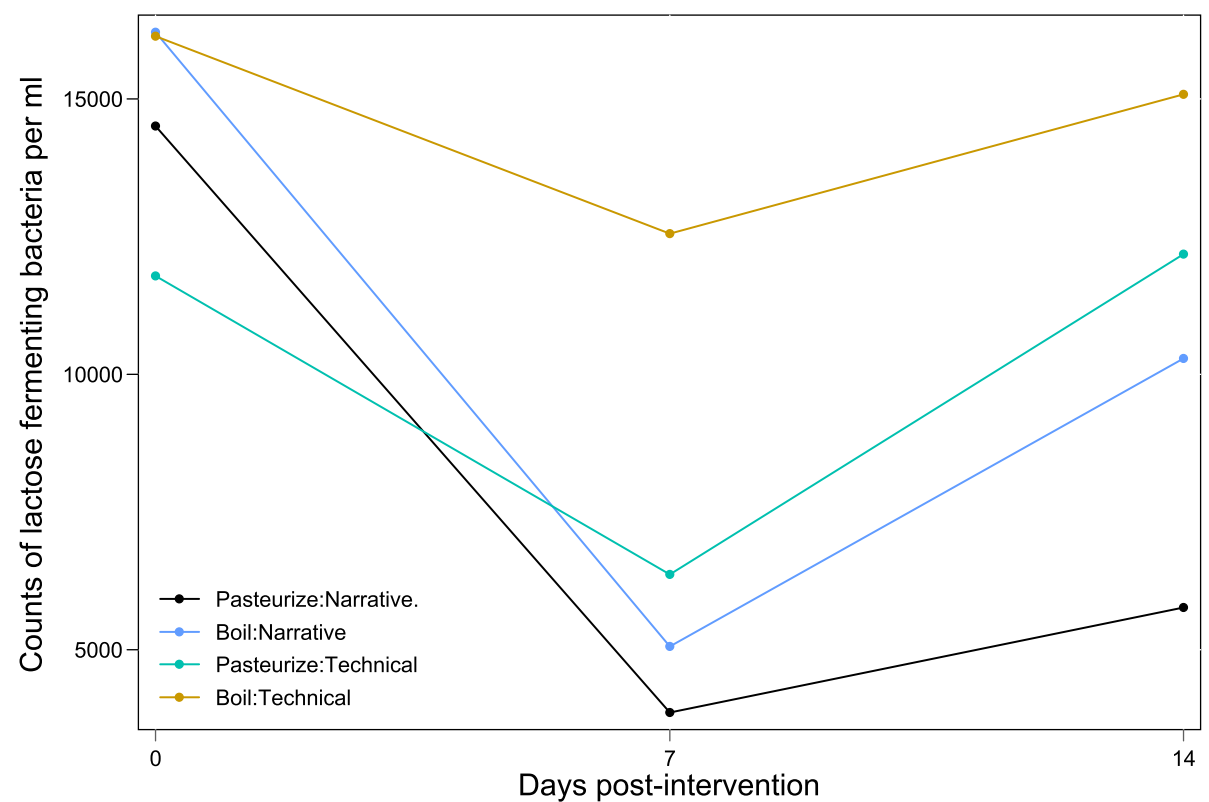

Fig. 5 Total bacterial counts in milk and containers across intervention strategies. See text for significant differences between plots

had lower TBCs compared to liquid samples $(\approx 64 \%$, $P<0.001)$. Increasing time between collecting samples and processing these in the lab was associated with a higher TBC $(\approx 13 \%$ per hour, $P=0.021)$. Each additional household member was associated with a TBC decrease $(\approx 9 \%, P=0.024)$. A Maasai women's pathogen avoidance score was related to $\mathrm{TBC}$ with a one sd increase in aversion (5 points) associated with about $\mathrm{a} \approx 15 \%$ decrease in TBC $(P=0.036)$.

\section{Person-level indicators of intervention effectiveness}

Intervention strategies had varying impacts on hygiene practices and sharing of intervention messages (Table 2). Holding other retained variables at their means, women given a narrative health message emphasizing pasteurization or boiling were expected to share with significantly more people, $\approx 1.4$ and $\approx 1.3$ people, respectively. Women with status as leaders in the church or local office were more likely to share with 0.54 more people, and every sd age increase was expected to share with $\approx 0.5$ more persons. For thermometer use, women receiving the $\mathrm{PN}$ message used the thermometers about seven additional times (predicted average $\approx 13$ times across a 2-week period) and women receiving the $\mathrm{BN}$ message about five additional times (predicted average $\approx 12$ times across a 2-week period) compared to women receiving the BT message. Maasai women who were more germ averse (i.e. higher scores on pathogen avoidant scale) used their thermometers significantly more, with a 1 sd increase (5 points on a 40-point scale) in aversion, increasing thermometer use by one time across the 2 weeks. No variables were related to soap use across the four Maasai villages. Maasai women receiving narrative messages had significantly higher retention of knowledge (average $71 \%$ on knowledge retention exam) compared to the BT households with women receiving the PN message scoring $\approx 14 \%$ higher and those receiving the $\mathrm{BN}$ message $\approx 8 \%$ higher when holding other variables, including education level, at their means. The number of self-reported hygiene practices also impacted knowledge scores with every additional hygienic practice associated with a $0.61 \%$ increase. The number of people with whom messages were shared was positively associated with test scores, with each additional sharing partner associated with a $0.46 \%$ increase in test score.

\section{Discussion}

A milk-hygiene intervention administered using a narrative health message that advocated and trained women to pasteurize milk produced the greatest increases in milk quality in Maasai pastoralist households compared to interventions administered in technical formats and/ or advocating boiling. Compared to women who were advised to boil their milk, women trained to pasteurize used their thermometers approximately 50\% more frequently during the intervention period and had significantly lower TBCs in their milk 7 days post-intervention. Importantly, this decrease occurred in households regardless of message format (i.e. narrative vs technical), suggesting that it is partially the pasteurization process itself that drives increased adoption of milk heat treatment. Along with better taste and lower labour demands, another benefit of pasteurization over boiling is that it would ultimately reduce exploitation of local 
Table 1 Reduced models for household intervention outcomes. IRR is incidence rate ratios from negative binomial regression while $B$ are beta coefficients from OLS. $R^{2}$ for sharing key messages is pseudo $R^{2}$ and adjusted $R^{2}$ for OLS models

\begin{tabular}{|c|c|c|c|c|c|c|c|c|}
\hline & \multicolumn{2}{|c|}{ Sharing Key Messages } & \multicolumn{2}{|c|}{ Thermometer Use } & \multicolumn{2}{|c|}{ Soap Use } & \multicolumn{2}{|c|}{ Knowledge Retention } \\
\hline & IRR & $95 \% \mathrm{Cl}$ & $B$ & $95 \% \mathrm{Cl}$ & $B$ & $95 \% \mathrm{Cl}$ & $B$ & $95 \% \mathrm{Cl}$ \\
\hline Boil Narrative & 1.67 & $0.68-4.10$ & 0.92 & $-0.96-2.80$ & -2.71 & $-10.89-5.46$ & $8.85^{* *}$ & $5.90-11.80$ \\
\hline Pasteuri Technical & $3.06^{* *}$ & $1.37-6.84$ & $5.33^{* *}$ & $3.48-7.18$ & 0.18 & $-7.53-7.88$ & 2.63 & $-0.11-5.38$ \\
\hline Pasteur Narrative & $3.34^{* *}$ & $1.53-7.25$ & $6.80^{* *}$ & $4.86-8.74$ & -1.23 & $-8.78-6.33$ & $13.73^{* *}$ & $10.93-16.54$ \\
\hline Observed sickness & 0.63 & $0.38-1.06$ & & & & & & \\
\hline Wife Age & $1.05^{* *}$ & $1.03-1.08$ & & & & & & \\
\hline Status ( $1=$ Yes $0=\mathrm{No}$ ) & $1.82^{*}$ & $1.05-3.13$ & & & & & & \\
\hline Household Size & 0.85 & $0.72-1.00$ & & & & & & \\
\hline Pathogen Avoidance & & & 0.20 & $0.07-0.34^{* *}$ & & & & \\
\hline Hygiene Practice & & & & & & & 0.33 & $-0.01-0.68$ \\
\hline Shared Numbers & & & & & & & 0.51 & $0.06-0.95^{*}$ \\
\hline Constant & & & 0.25 & $-3.51-4.02$ & 20.690 & $15.39-25.99^{* *}$ & 72.02 & $69.27-74.77^{* *}$ \\
\hline$R^{2}$ & 0.14 & & 0.51 & & -0.02 & & & 0.61 \\
\hline Prob>chi2 & 0.00 & & & & & & & \\
\hline Log Likelihood & -137.47 & & & & & & & \\
\hline LR chi2 & 43.40 & & & & & & & \\
\hline Obs & 104 & & 85 & & 104 & & & 104 \\
\hline
\end{tabular}

${ }^{*} p<0.05 ; * * 0<0.01$

wood resources as it is a lower level heat treatment. Reducing exploitation of wood resources is particularly critical in pastoralist communities that inhabit arid environments where these resources are already scarce.

Given the potential benefits of milk pasteurization to household health, incomes, and the environment, resources should be devoted towards developing a pasteurization thermometer that is long-lasting, easy to use, and affordable to pastoralist communities. We are currently developing a third-generation thermometer with a unit cost between 4 and 5 USD. We chose this point given that it is equivalent to the sale of one to two chickens in our communities and chickens are one of the few resources Maasai women hold selling rights over. Development of an affordable pasteurization thermometer holds public health consequences outside pastoralist communities, given that a large majority of dairy products consumed in LMICs, estimated between 75 and 90\% in sub-Saharan Africa (Bertu et al. 2010), come from smallholder systems that operate outside national quality control standards and regulations while compliance rates within regulated systems can be low (Kiambi et al. 2018). Consequently, public health interventions to improve milk quality across LMICs will need to be targeted at changing consumer practices to ensure the full nutritional benefits of milk are realized.

More generally, our results hold important insights into the development of sustainable and scalable public health interventions aimed at low-health-literacy and hard-to-reach communities such as pastoralists. Narrative risk messages elicited greater retention and sharing of intervention messages. Sharing was associated with retention of key intervention messages, a result consistent with the protégé effect, which describes why teachers are more likely to retain information (Chase et al. 2009). End-user sharing of narrative messages is more likely to result in the diffusion of healthy behaviours across hard-to-reach communities because acceptance of narrative messages, in contrast to technical messages, depends less on the perceived expertise of the messenger (e.g. health professionals) and more upon the similarity between the messenger and the person receiving the message (Kreuter et al. 2007). Narratives further promote acceptance through limiting "counterarguing", which occurs when a person's previously held beliefs prevent conveyance of risk (Green and Brock 2000). Indeed, narratives were the most effective message in this study even though half of our study participants believed that milk could not contain bacteria or that drinking milk could make a person sick. We suspect that limiting counterarguing is particularly critical in low-health-literacy populations because they may possess views inconsistent with established biomedical realities (e.g. concepts of contagion). To gauge the full potential of narrative messages to promote "self-propagating" interventions, more research is needed to identify the targeting strategies (i.e. to 
Table 2 Reduced models for household intervention outcomes. IRR is incidence rate ratios from negative binomial regression while $B$ are beta coefficients from OLS. $R^{2}$ for sharing key messages is pseudo $R^{2}$ and adjusted $R^{2}$ for OLS models

\begin{tabular}{|c|c|c|c|c|c|c|c|c|}
\hline & Sharing & lessages & Thermo & ter Use & Soap Us & & Knowled & Retention \\
\hline & IRR & $95 \% \mathrm{Cl}$ & $B$ & $95 \% \mathrm{Cl}$ & $B$ & $95 \% \mathrm{Cl}$ & $B$ & $95 \% \mathrm{Cl}$ \\
\hline Boil Narrative & 1.67 & $0.68-4.10$ & 0.92 & $-0.96-2.80$ & -2.71 & $-10.89-5.46$ & $8.85^{* *}$ & $5.90-11.80$ \\
\hline Pasteuri Technical & $3.06^{* *}$ & $1.37-6.84$ & $5.33^{* *}$ & $3.48-7.18$ & 0.18 & $-7.53-7.88$ & 2.63 & $-0.11-5.38$ \\
\hline Pasteur Narrative & $3.34^{* *}$ & $1.53-7.25$ & $6.80^{* *}$ & $4.86-8.74$ & -1.23 & $-8.78-6.33$ & $13.73^{* *}$ & $10.93-16.54$ \\
\hline Observed sickness & 0.63 & $0.38-1.06$ & & & & & & \\
\hline Wife Age & $1.05^{* *}$ & $1.03-1.08$ & & & & & & \\
\hline Status $(1=$ Yes $0=\mathrm{No}$ ) & $1.82^{*}$ & $1.05-3.13$ & & & & & & \\
\hline Household Size & 0.85 & $0.72-1.00$ & & & & & & \\
\hline Pathogen Avoidance & & & 0.20 & $0.07-0.34^{* *}$ & & & & \\
\hline Hygiene Practice & & & & & & & 0.33 & $-0.01-0.68$ \\
\hline Shared Numbers & & & & & & & 0.51 & $0.06-0.95^{*}$ \\
\hline Constant & & & 0.25 & $-3.51-4.02$ & 20.690 & $15.39-25.99^{* *}$ & 72.02 & $69.27-74.77^{* *}$ \\
\hline$R^{2}$ & 0.14 & & 0.51 & & -0.02 & & & 0.61 \\
\hline Prob>chi2 & 0.00 & & & & & & & \\
\hline Log Likelihood & -137.47 & & & & & & & \\
\hline LR chi2 & 43.40 & & & & & & & \\
\hline Obs & 104 & & 85 & & 104 & & & 104 \\
\hline
\end{tabular}

${ }^{*} p<0.05 ; * * 0<0.01$

whom should intervention be administered) that will maximize intervention diffusion across communities. Studies are also needed to track implementation fidelity and transmission from initial intervention targets to subsequent learners over the long term. Insights from this research promise to inform the development of public health interventions that enable sustained positive health behaviours and outcomes across low-health-literacy, hard-to-reach communities within LMICs.

However, the analysis was confined to interventions administered in Western populations, owing to the lack of similar research in LMIC countries. Narrative approaches have found success in LMICs in the form of "edutainment" (e.g. soap operas on tv or radio, cellphone games) (Usdeen 2009), but these types of messages are unlikely to reach many rural pastoral households that often lack power and appropriate technological inputs (cellphones/ radios with battery charge).

\section{Conclusions}

Providing pastoralist communities with the technology and training to pasteurize milk can increase milk quality and thus help to secure the nutritional benefits associated with dairy production. Longitudinal research is needed, however, to determine whether the milk quality increases promoted by pasteurization translate to better health outcomes in pastoralist communities. More generally, this study demonstrated that providing intervention messages in narrative formats may increase the likelihood of positive behavioural change and within-community sharing of health messages. Future work among low-health-literacy and hard-to-reach communities should consider the use of narrative health messages to both sustain and scale up public health interventions.

\section{Additional file}

Additional file 1: Figure S1. Thermometer design and thermometer being used in a Maasai household. (DOCX 1886 kb)

\section{Acknowledgements}

We are grateful to the Maasai for their hospitality, participation and input. A special thank you to our local research assistants, Willum Kanunga, Samwel Haiyo, Danny Lekton, Emmanuel Laizer, Isaya Rumas, Godfrey Laizer, and

Tureto Katai.

\section{Funding}

This project was funded by a National Science Foundation grant titled "Ecological and Socio-Economic Factors Impacting Maintenance and Dissemination of Antibiotic Resistance in the Greater Serengeti Ecosystem" (grant \#1216040).

\section{Availability of data and materials}

The datasets used and/or analysed during the current study are available from the corresponding author on reasonable request.

Authors' contributions

MAC and DRC conceived and designed the study and wrote the manuscript. MAC conducted the data analysis. MAC, BM, MS, and JB designed and conducted the laboratory work. AM and PVC designed and piloted the smart 
thermometer technology used in the intervention. All authors have read and approved the manuscript.

\section{Ethics approval and consent to participate}

This study was approved by the Washington State Institutional Review Board (\#12533). Written or verbal consent was obtained from all subjects. Verbal consent was witnessed and formally recorded.

\section{Consent for publication}

Not applicable

\section{Competing interests}

Authors AM and PVC have registered a patent for the pasteurization smart thermometer used in this study (patent: 15/909,718). The other authors declare that they have no competing interests.

\section{Publisher's Note}

Springer Nature remains neutral with regard to jurisdictional claims in published maps and institutional affiliations.

\section{Author details}

${ }^{1}$ Paul G. Allen School for Global Animal Health, Washington State University, 240 SE Ott Road, Pullman, WA 99164-7090, USA. ²Department of Anthropology, Washington State University, Pullman, WA, USA. ${ }^{3}$ Voiland College of Engineering and Architecture, Washington State University, Pullman, WA, USA. ${ }^{4}$ Center for Entrepreneurial Studies, Washington State University, Pullman, WA, USA. ${ }^{5}$ Nelson Mandela African Institution of Science and Technology, Arusha, Tanzania.

\section{Received: 6 December 2018 Accepted: 19 March 2019}

\section{Published online: 30 April 2019}

\section{References}

Ahmed, A.I., B.E. Mohamed, N.M.E. Yousif, B. Faye, and G. Loiseau. 2012. Antimicrobial activity and antibiotic resistance of $L A B$ isolated from Sudanese traditional fermented camel (Camelus dromedarius) milk gariss. The International Journal of Biochemistry 2: 129-136.

Allen, Lindsay H. 1994. Nutritional influences on linear growth: A general review. European Journal of Clinical Nutrition 48: S75-S89.

Abebe, Mekuria, Daniel Asrat, Yimtubezinash Woldeamanuel, and Genene Tefera. 2013. Identification and antimicrobial susceptibility of Staphylococcus aureus isolated from milk samples of dairy cows and nasal swabs of farm workers in selected dairy farms around Addis Ababa, Ethiopia. African Journal of Microbiology Research 7: 3501-3510.

Ateba, Collins N., Moses Mbewe, Modisane S. Moneoang, and Cornelius C. Bezuidenhout. 2010. Antibiotic-resistant Staphylococcus aureus isolated from milk in the Mafikeng Area, North West province, South Africa. South African Journal of Science 106: 1-6.

Bakhtsiyarava, Maryia, Kathryn Grace, and Raphael J. Nawrotzki. 2017. Climate, birth weight, and agricultural livelihoods in Kenya and Mali. American Journal of Public Health 108: S144-S150. https://doi.org/10.2105/AJPH.2017.304128.

Barasa, M., A. Catley, D. Machuchu, H. Laqua, E. Puot, D. Tap Kot, and D. Ikiror. 2008. Foot-and-mouth disease vaccination in South Sudan: Benefit-cost analysis and livelihoods impact. Transboundary and Emerging Diseases 55: 339-351.

Bertu, W.J., M. Dapar, A.M. Gusi, S.S. Ngulukun, S. Leo, and L.D. Jwander. 2010. Prevalence of brucella antibodies in marketed milk in Jos and environs. African Journal of Food Science 4: 062-064.

Black, Robert E., Cesar G. Victora, Susan P. Walker, Zulfiqar A. Bhutta, Parul Christian, Mercedes de Onis, Majid Ezzati, et al. 2013. Maternal and child undernutrition and overweight in low-income and middle-income countries. The Lancet 382: 427-451. https://doi.org/10.1016/S0140-6736(13)60937-X Elsevier.

Caudell, Mark A., Colette Mair, Murugan Subbiah, Louise Matthews, Robert J. Quinlan, Marsha B. Quinlan, Ruth Zadoks, Julius Keyyu, and Douglas R. Call. 2018. Identification of risk factors associated with carriage of resistant Escherichia coli in three culturally diverse ethnic groups in Tanzania: A biological and socioeconomic analysis. The Lancet Planetary Health 2: e489e497. https://doi.org/10.1016/S2542-5196(18)30225-0.

Caudell, Mark A., Marsha B. Quinlan, Murugan Subbiah, Douglas R. Call, Casey J. Roulette, Jennifer W. Roulette, Adam Roth, Louise Matthews, and Robert J.
Quinlan. 2017. Antimicrobial use and veterinary care among agro-pastoralists in Northern Tanzania. PLoS One 12: e0170328.

Chase, Catherine C., Doris B. Chin, Marily A. Oppezzo, and Daniel L. Schwartz. 2009. Teachable agents and the protégé effect: Increasing the effort towards learning. Journal of Science Education and Technology 18: 334-352.

Dror, Daphna K., and Lindsay H. Allen. 2011. The importance of milk and other animal-source foods for children in low-income countries. Food and Nutrition Bulletin 32: 227-243. https://doi.org/10.1177/156482651103200307.

Duguma, Belay, and Geert P.J. Janssens. 2015. Assessment of dairy farmers' hygienic milking practices and awareness of cattle and milk-borne zoonoses in Jimma, Ethiopia. Assessment 45-54.

Duncan, Lesley A., Mark Schaller, and Justin H. Park. 2009. Perceived vulnerability to disease: Development and validation of a 15-item self-report instrument. Personality and Individual Differences 47: 541-546.

Food and Agriculture Organization of the United Nations (FAO). 2008. Milk and dairy products. Animal Production and Health Divisions. Rome: FAO.

Fratkin, Elliot, Martha A. Nathan, and Eric A. Roth. 2006. Is settling good for pastoralists? The effects of pastoral sedentarization on children's nutrition, growth, and health among Rendille and Ariaal of Marsabit District, northern Kenya. Nairobi, Kenya: International Livestock Research Institute.

Galli, Claudio, and Patrizia Risé. 2017. Chapter 4 - the role of fats in milk and dairy products in nutrition and health from infancy to adulthood A2 - Watson, Ronald Ross. In Dairy in human health and disease across the lifespan, ed. Robert J. Collier and Victor R. Preedy, 57-72. Academic Press. https://doi.org/ 10.1016/B978-0-12-809868-4.00004-2.

Galvin, Kathleen A. 1992. Nutritional ecology of pastoralists in dry tropical Africa. American Journal of Human Biology 4: 209-221.

Geoghegan, Claire, M. Robertson, and W. Getz. 2013. My animals, my health, my people: Linking human, livestock and zoonotic disease awareness with local farming and food practices to improve rural health in KwzZulu-Natal, South Africa. 14th International Conference of the Association of Institutions for Tropical Veterinary Medicine. Indaba Hotel, Johannesburg, South Africa, 2629 August 2013.

Goddu, Anna P., Katie E. Raffel, and Monica E. Peek. 2015. A story of change: The influence of narrative on African-Americans with diabetes. Patient Education and Counseling 98: 1017-1024. https://doi.org/10.1016/j.pec.2015.03.022.

Green, Melanie C., and Timothy C. Brock. 2000. The role of transportation in the persuasiveness of public narratives. Journal of Personality and Social Psychology 79: 701.

Hjertholm, Katrine G., Per Ole Iversen, Gerd Holmboe-Ottesen, Ibrahimu Mdala, Alister Munthali, Kenneth Maleta, Zumin Shi, Elaine Ferguson, and Penjani Kamudoni. 2017. Maternal dietary intake during pregnancy and its association to birth size in rural Malawi: A cross-sectional study. Maternal \& Child Nutrition 14: e12433. https://doi.org/10.1111/mcn.12433.

Homewood, Katherine. 1992. Development and the ecology of Maasai pastoralist food and nutrition. Ecology of Food and Nutrition 29: 61-80.

Homewood, Katherine. 1995. Development, demarcation and ecological outcomes in Maasailand. Africa 65: 331-350.

Homewood, Katherine, Patti Kristjanson, and Pippa Trench. 2009. Staying Maasai?: Livelihoods, conservation and development in East African rangelands. In Studies in human ecology and adaptation series, ed. D. Bates and L. Lozny, 5. New York: Springer.

Hoppe, Camilla, Christian Mølgaard, and Kim F. Michaelsen. 2006. Cow's milk and linear growth in industrialized and developing countries. Annual Review of Nutrition 26: 131-173.

Ibrahim, Fouad N. 2001. The drinking ritual among the Maasai. In Drinking: Anthropological approaches, ed. Igor De Garine and Valerie De Garine, 87-95. New York: Berghahn Books.

Jans, Christoph, Axel Merz, Sophia Johler, Mario Younan, Sabine A. Tanner, Dasel Wambua Mulwa Kaindi, John Wangoh, Bassirou Bonfoh, Leo Meile, and Taurai Tasara. 2017. East and West African milk products are reservoirs for human and livestock-associated Staphylococcus aureus. Food Microbiology 65: 64-73.

Karimuribo, Esron D., Lughano J. Kusiluka, Robinson H. Mdegela, Angolwisye M. Kapaga, Calvin Sindato, and Dominic M. Kambarage. 2005. Studies on mastitis, milk quality and health risks associated with consumption of milk from pastoral herds in Dodoma and Morogoro regions, Tanzania. Journal of Veterinary Science 6: 213-221.

Kiambi, Stella, Pablo Alarcon, Jonathan Rushton, Maurice K. Murungi, Patrick Muinde, James Akoko, Gabriel Aboge, et al. 2018. Mapping Nairobi's dairy food system: An essential analysis for policy, industry and research. Agricultural Systems 167: 47-60. https://doi.org/10.1016/j.agsy.2018.08.007. 
Koné, Valentin Bognan, Kristina Roesel, Gilbert Fokou, Kohei Makita, Delia Grace, Gnabeli Y. Roch, and Bassirou Bonfoh. 2014. Boiling milk disrupts the social order of communities in Mali. In Food safety and informal markets. Animal products in sub-Saharan Africa, Kristina Roesel and Delia Grace. London: Routledge.

Kreuter, Matthew W., Melanie C. Green, Joseph N. Cappella, Michael D. Slater, Meg E. Wise, Doug Storey, Eddie M. Clark, Daniel J. O'Keefe, Deborah O. Erwin, and Kathleen Holmes. 2007. Narrative communication in cancer prevention and control: A framework to guide research and application. Annals of Behavioral Medicine 33: 221-235.

Lawson, David W., Monique Borgerhoff Mulder, Margherita E. Ghiselli, Esther Ngadaya, Bernard Ngowi, Sayoki G.M. Mfinanga, Kari Hartwig, and Susan James. 2014. Ethnicity and child health in northern Tanzania: Maasai pastoralists are disadvantaged compared to neighbouring ethnic groups. PLoS One 9: e110447.

Lindtjørn, Bernt, Tadesse Alemu, and Bjarne Bjorvatn. 1993. Dietary pattern and state of nutrition among children in drought-prone areas of southern Ethiopia. Annals of Tropical Paediatrics 13: 21-32.

Little, Michael A., Sandra J. Gray, and Benjamin C. Campbell. 2001. Millk consumption in African pastoral peoples. In Drinking: Anthropological approaches, ed. Igor De Garine and Valerie De Garine, 66-86. New York: Berghahn Books.

Long, J. Scott, and Jeremy Freese. 2006. Regression models for categorical dependent variables using Stata. Second. College Station, Texas: Stata press.

Lubote, Robert, Francis Shahada, and Athanasia Matemu. 2014. Prevalence of Salmonella spp. and Escherichia coli in raw milk value chain in Arusha, Tanzania. American Journal of Research Communication 2: 1-13.

Ludvigsson, J.F., and J. Ludvigsson. 2007. Milk consumption during pregnancy and infant birthweight. Acta Paediatrica 93: 1474-1478. https://doi.org/10. 1111/j.1651-2227.2004.tb02632.x Blackwell Publishing Ltd.

Mangesho, Peter Ernest, Moses Ole Neselle, Esron D. Karimuribo, James E. Mlangwa, Kevin Queenan, Leonard E.G. Mboera, Jonathan Rushton, et al. 2017. Exploring local knowledge and perceptions on zoonoses among pastoralists in northern and eastern Tanzania. PLoS Neglected Tropical Diseases 11: e0005345. https://doi.org/10.1371/journal.pntd.0005345.

Mbuk, E.U., J.K.P. Kwaga, J.O.O. Bale, L.A. Boro, and J.U. Umoh. 2016. Coliform organisms associated with milk of cows with mastitis and their sensitivity to commonly available antibiotics in Kaduna State, Nigeria. Journal of Veterinary Medicine and Animal Health 8: 228-236.

McCabe, J. Terrence, Paul W. Leslie, and Laura DeLuca. 2010. Adopting cultivation to remain pastoralists: The diversification of Maasai livelihoods in northern Tanzania. Human Ecology 38: 321-334. 10.1007/s. doi:doi:10745-0 10-93 12-8.

Michaelsen, Kim F. 2013. Cow's milk in the prevention and treatment of stunting and wasting. Food and Nutrition Bulletin 34: 249-251.

Moran, Meghan Bridgid, Lauren B. Frank, Joyee S. Chatterjee, Sheila T. Murphy, and Lourdes Baezconde-Garbanati. 2016. A pilot test of the acceptability and efficacy of narrative and non-narrative health education materials in a low health literacy population. Journal of Communication in Healthcare 9: 40-48.

Msoffe, Fortunata U., Shem C. Kifugo, Mohammed Y. Said, Moses Ole Neselle, Paul Van Gardingen, Robin S. Reid, Joseph O. Ogutu, Mario Herero, and Jan De Leeuw. 2011. Drivers and impacts of land-use change in the Maasai Steppe of northern Tanzania: An ecological, social and political analysis. Journal of Land Use Science 6: 261-281.

Muehlhoff, Ellen, Anthony Bennett, and Deirdre McMahon. 2013. Milk and dairy products in human nutrition. Rome: Food and Agriculture Organization of the United Nations (FAO)

Negash, Fikrineh, Estefanos Tadesse, and Tatek Woldu. 2012. Microbial quality and chemical composition of raw milk in the Mid-Rift Valley of Ethiopia. African Journal of Agricultural Research 7: 4167-4170.

Ngasala, uma J. Bukuku, Hezron Emmanuel Nonga, and Mkumbukwa Madundo Angelo Mtambo. 2015. Assessment of raw milk quality and stakeholders' awareness on milk-borne health risks in Arusha City and Meru District, Tanzania. Tropical Animal Health and Production 47: 927-932. https://doi.org/ 10.1007/s11250-015-0810-y.

Roug, Annette, Andres Perez, Jonna A.K. Mazet, Deana L. Clifford, Elizabeth VanWormer, Goodluck Paul, Rudovick R. Kazwala, and Woutrina A. Smith. 2014. Comparison of intervention methods for reducing human exposure to Mycobacterium bovis through milk in pastoralist households of Tanzania. Preventive Veterinary Medicine 115: 157-165.

Roulette, Casey J., Mark A. Caudell, Jennifer W. Roulette, Robert J. Quinlan, Marsha B. Quinlan, Murugan Subbiah, and Douglas R. Call. 2017. A two-month follow-up evaluation testing interventions to limit the emergence and spread of antimicrobial resistant bacteria among Maasai of northern Tanzania. BMC Infectious Diseases 17: 770.

Roulette, Jennifer W., Casey J. Roulette, Robert J. Quinlan, Douglas R. Call, B.S. Hewlett, Mark A. Caudell, and Marsha B. Quinlan. 2018. Children's ethnobiological notions of contamination and contagions among Maasai agro-pastoralists of northern Tanzania. Journal of Ethnobiology 38: 261-275.

Sadler, Kate, Carol Kerven, Muriel Calo, Michael Manske, and Andrew Catley. 2010. The fat and the lean: Review of production and use of milk by pastoralists. Pastoralism 1: 291-324.

Sangeda, Anthony Z., and David D. Maleko. 2018. Rangeland condition and livestock carrying capacity under the traditional rotational grazing system in northern Tanzania. Livestock Research for Rural Development 30: 5

Schoder, Dagmar, Andreas Maichin, Benedict Lema, and John Laffa. 2013. Microbiological quality of milk in Tanzania: From Maasai stable to African consumer table. Journal of Food Protection ${ }^{\oplus} 76$ : 1908-1915.

Shen, Fuyuan, Vivian C. Sheer, and Ruobing Li. 2015. Impact of narratives on persuasion in health communication: A meta-analysis. Journal of Advertising 44: 105-113. https://doi.org/10.1080/00913367.2015.1018467.

Shija, Fortunate. 2013. Assessment of milk handling practices and bacterial contaminations along the dairy value chain in Lushoto and Handeni districts, Tanzania. Morogoro, Tanzania: Sokoine University of Agriculture MSc Thesis.

StataCorp. 2012. Stata statistical software: Release 13. College Station, TX: Stata Corp LP.

Suleiman, A.B., V.J. Umoh, J.K.P. Kwaga, and S.J. Shaibu. 2013. Enterotoxigenicity and antibiotic resistance of Staphylococcus aureus isolated from sub-clinical bovine mastitis milk in plateau state, Nigeria. Research Journal of Microbiology 8: 101.

Usdeen, S. 2009. 'Edutainment'in South Africa: A force for change in health. [An Interview with Shereen Usdin].

Welearegay, Haile, Zelalem Yilma, and Yosef Tekle-Giorgis. 2012. Hygienic practices and microbiological quality of raw milk produced under different farm size in Hawassa, southern Ethiopia. Agricultural Research and Review 1(4): 1132-142.

Wiley, Andrea S. 2017. Chapter 11 - Cow's milk consumption and child growth A2 - Watson, Ronald Ross. In Dairy in human health and disease across the lifespan, ed. Robert J. Collier and Victor R. Preedy, 155-166. Academic Press. doi:https://doi.org/10.1016/B978-0-12-809868-4.00011-X.

Xueqin, D.U., Kun Zhu, Angelika Trube, Qian Zhang, Guansheng Ma, Hu Xiaoqi, David R. Fraser, and Heather Greenfield. 2004. School-milk intervention trial enhances growth and bone mineral accretion in Chinese girls aged 10-12 years in Beijing. British Journal of Nutrition 92: 159-168.

Zanella, G.N., J.M.G. Mikcha, E. Bando, V.L.D. Siqueira, and M. Machinski. 2010. Occurrence and antibiotic resistance of coliform bacteria and antimicrobial residues in pasteurized cow's milk from Brazil. Journal of Food Protection ${ }^{\circledR} 73$ : 1684-1687.

\section{Submit your manuscript to a SpringerOpen ${ }^{\circ}$ journal and benefit from:}

- Convenient online submission

- Rigorous peer review

- Open access: articles freely available online

High visibility within the field

- Retaining the copyright to your article

Submit your next manuscript at $>$ springeropen.com 